\title{
Escribiendo memorias de la dictadura: Las asignaturas pendientes del cine argentino
}

Writing Memories of the Dictatorship: Ongoing Issues in Argentinean Cinema Écrits des mémoires de la dictature : les matières en attente du cinéma argentin

Susana Kaiser

\section{OpenEdition}

\section{Journals}

Edición electrónica

URL: http://journals.openedition.org/rccs/1715

DOI: $10.4000 /$ rccs. 1715

ISSN: 2182-7435

Editor

Centro de Estudos Sociais da Universidade de Coimbra

Edición impresa

Fecha de publicación: 1 marzo 2010

Paginación: 101-125

ISSN: 0254-1106

Referencia electrónica

Susana Kaiser, «Escribiendo memorias de la dictadura: Las asignaturas pendientes del cine argentino », Revista Crítica de Ciências Sociais [En línea], 88 | 2010, Puesto en línea el 01 octubre 2012, consultado el 19 abril 2019. URL : http://journals.openedition.org/rccs/1715 ; DOI : 10.4000/ rccs. 1715 


\title{
Escribiendo memorias de la dictadura: Las asignaturas pendientes del cine argentino
}

\begin{abstract}
Por más de un cuarto de siglo, el cine argentino ha venido escribiendo memorias de la última dictadura (1976-1983). La cámara convertida en historiadora se encuentra frente a ciertos desafíos. Qué pasó, por qué pasó, cómo pudo suceder, quiénes son los responsables, y cuáles son las secuelas en el tejido social, son algunas de las preguntas en busca de respuestas. Este artículo explora cómo se ha representado la dictadura y analiza cuatro películas de ficción producidas y estrenadas en este siglo veintiuno: Kamchatka (Marcelo Piñeyro, 2002), Cautiva (Gastón Biraben, 2003), Hermanas (Julia Solomonoff, 2004), y Crónica de una fuga (Israel Adrián Caetano, 2006).
\end{abstract}

Palabras clave: Argentina; cine; derechos humanos; dictadura militar; memoria; terrorismo de Estado; trauma.

Palavras-chave: Argentina; cinema; direitos humanos; ditadura militar; memória; terrorismo de Estado; trauma.

\section{Introducción}

Por más de un cuarto de siglo, el cine argentino ha venido escribiendo memorias de la última dictadura (1976-1983), esos años siniestros durante los cuales la violencia del terrorismo de Estado dejó un legado que se estima en 30000 desaparecidos. La cámara de cine convertida en historiadora se enfrenta a ciertos desafíos. Qué pasó, por qué pasó, cómo pudo suceder, quiénes son los culpables y responsables, o cuáles son las secuelas en el cuerpo social, son algunas de las preguntas en busca de respuestas. Cada película que aborda ese período histórico, ya sea documental o de ficción, contesta algunas de ellas y mantiene silencios sobre otras.

Sabemos que las memorias de una sociedad son divergentes y los hechos históricos son recordados de diferentes maneras por las varias comunidades mnemónicas que coexisten en ella. Hubo una dictadura pero hay muchas memorias de ella. Mi interés es sobre la memoria "ejemplar" según la define Todorov, esa memoria que está al servicio de la justicia y por lo tanto a 
favor de los reclamos por la verdad y el fin de la impunidad. Las diferentes memorias y versiones históricas sobre lo que pasó, interactúan, coexisten, y compiten en representaciones documentales y ficcionales que el cine argentino ha producido. ${ }^{1}$

Este artículo explora cómo se ha representado la dictadura y analiza cuatro películas de ficción producidas y estrenadas en este siglo veintiuno: Kamchatka (Marcelo Piñeyro, 2002), Cautiva (Gastón Biraben, 2003), Hermanas (Julia Solomonoff, 2004), y Crónica de una fuga (Israel Adrián Caetano, 2006). ${ }^{2}$ Importa destacar el momento histórico y político de producción porque los filmes construyen versiones históricas y son productos del contexto en que son realizados. Se trata de imágenes fílmicas que recrean los años de plomo a partir de una distancia de dos décadas desde el inicio de la apertura democrática. Los comienzos del gobierno civil fueron promisorios para la causa de los derechos humanos. Esto no duró mucho. La comisión para la desaparición de personas y los juicios a las juntas militares fueron seguidos por un proceso de legalización de la impunidad (leyes e indultos por decreto presidencial). ${ }^{3}$ Pero gracias a la persistencia y al coraje de los activistas de derechos humanos, el muro de la impunidad se va derrumbando lentamente. Ha habido cambios significativos en las políticas oficiales de memoria y los represores están siendo juzgados y condenados. ${ }^{4}$

Mi análisis considera: los temas que se tocan y los que se evaden, qué es lo diferente en estos filmes, cómo se representa al horror, cómo transmiten la sensación de vivir bajo el terror, cómo insertan la presencia de este pasado traumático en la Argentina contemporánea, qué memorias escriben, cuáles son sus contribuciones a lo que ya sabemos sobre esos años. Me interesa discutir estos filmes en cuanto a su valor como textos históricos. Lo que sabemos sobre lo que sucedió nos permite evaluar lo que las recreaciones ficcionales de la dictadura ofrecen. Es lo que propone Rosentone (2000: 62), juzgar los filmes históricos en base al conocimiento del pasado que representan. Tenemos mucha información sobre lo ocurrido durante

\footnotetext{
${ }^{1}$ Toca aclarar mi posición. Viví durante esos años en Buenos Aires, mi ciudad natal, y estoy alineada con las demandas y acciones de las organizaciones de derechos humanos, en particular con las Madres y Abuelas de Plaza de Mayo e H.I.J.O.S. (Hijos por la Identidad y la Justicia contra el Olvido y el Silencio), madres, abuelas e hijos de desaparecidos respectivamente. También agradezco a Violeta Velázquez su asistencia en la investigación.

${ }^{2}$ Una versión preliminar y parcial de este trabajo fue presentada en una conferencia en la University of Oregon (Kaiser, 2008).

${ }^{3}$ Comisión Nacional para la desaparición de personas (CONADEP) (1984); Juicios a las juntas (1985). Leyes de Impunidad: "Punto Final" (1986) y "Obediencia Debida" (1987). Indultos por decreto presidencial (1989 y 1990).

${ }^{4}$ En 2005, la Corte Suprema ratificó la nulificación de las leyes de impunidad.
} 
esos años: testimonios de sobrevivientes, datos recopilados por los organismos de derechos humanos, documentación obtenida mediante investigaciones y causas judiciales. Aunque aún haya muchos detalles por conocer, se sabe que pasó y cómo funcionó el sistema. Esto nos permite decodificar los mensajes que las imágenes transmiten y verificar si lo representado corresponde con los hechos documentados.

Sostengo que se ha hecho mucho por representar ese pasado y que estas nuevas películas demuestran que hay enfoques distintos y originales para narrar lo que fue la dictadura y las secuelas que dejó. Pero considero que queda mucho por hacer. Muchos temas tabú de los que todavía no se habla y que el cine aun no intentó representar, a los que se agregan otros que necesitan ser tratados desde otras perspectivas. El artículo está organizado así: 1) unas notas sobre la relación entre cine y memoria; 2) un resumen de lo que el cine argentino ha contado y callado desde que terminó la dictadura; 3) el análisis de las cuatro películas citadas.

\section{Sobre cine y memoria}

Sabemos que la memoria es una relación presente-pasado que está en permanente [re]construcción, a nivel individual y social, y que las memorias de una sociedad se negocian y definen en un contexto de debate (Halbwachs, 1992; Fentress y Wickham, 1992). Cada generación, cada contexto histórico, y cada coyuntura política generan nuevas perspectivas a través de las cuales miramos al pasado. La relevancia que las memorias de la dictadura tienen en la sociedad influencia la producción cultural sobre la misma. Dependiendo del momento de producción y de la mirada del cineasta, los filmes sobre la dictadura presentan memorias distintas de una misma historia.

No podemos recordar todo. Pensemos en la pesadilla del memorioso Funes del cuento de Borges, condenado a recordar permanente y detalladamente todo. Es por eso que el proceso de construcción de memorias funciona como una máquina editora que selecciona qué olvidar y qué recordar. Los filmes también editan el pasado, resaltando ciertos aspectos y minimizando o ignorando otros. Contribuyen así a la transmisión y construcción de versiones diferentes, y a menudo contradictorias, sobre los mismos hechos. En este proceso es tan importante lo que se dice como lo que se calla, lo que se recuerda como lo que se olvida. En vez de ser lo opuesto a recordar, la amnesia es una forma de memoria (Huyssen, 1995). O como sugiere Todorov (1995: 14), la memoria es precisamente la interacción entre lo que se recuerda y lo que se olvida.

El cine tiene el potencial de activar la "máquina editora" de lo que los espectadores recuerdan y olvidan sobre la dictadura. De hecho, cada vez es 
mayor el papel que juega el cine como fuente de conocimiento histórico, ya se trate de la historia oficial, la historia alternativa, o las memorias de ciertos grupos (Ferro y Planchais, 1997; Landy, 2000; Rosentone, 2000). A pesar de los historiadores que menosprecian estas versiones históricas para consumo masivo, hay mucha gente que aprende sobre el pasado a través de filmes y no de libros de historia. Argumentando que el cine presenta nuevas contribuciones a cómo imaginamos y comprendemos el pasado, Rosentone (2000: 50) sugiere que los filmes son un símbolo perturbador de un mundo posliterato en donde la gente sabe leer pero no lo hace. Rosenthal (1999: xix) nota que aun cuando el mayor criticismo al género "docudrama" se centra en los efectos sobre las audiencias - un público incapaz de comprender la diferencia entre realidad y ficción que es fácilmente manipulado no hay muchos datos en que basar esas afirmaciones. Sabemos poco sobre cómo perciben los espectadores estos filmes, si como realidades históricas o invenciones, y sobre cuáles son los efectos de estar expuesto a estas representaciones.

Con referencia a la relevancia del cine en instalar temas en la esfera pública, Ferro y Planchais (1997: 12) notan que en el año del estreno de Reds (1981) se publicaron más artículos sobre la Revolución Soviética que en ningún otro momento, ni siquiera para el aniversario de Octubre. Rosenthal (1999: xvii) considera que Gandhi (1982) y Malcom X (1992) fueron pioneros en la formación de opinión pública sobre temas políticos clave tales como la desobediencia civil y el black pride. Estudios sobre cómo se recuerdan pasados traumáticos y violentos coinciden en que el cine moldea memorias y refuerza ciertas opiniones. Esto incluye filmes sobre Vietnam cuyas imágenes son fuentes de información histórica (Sturken, 1997); estudiantes que aprendieron sobre la Guerra Civil Española a través del cine (Igartúa y Páez, 1997); debates sobre Schindler's List (1993) como una forma de texto histórico del Holocausto que contribuye a transformar lo que entendemos por historia y moldea memoria e identidad nacional (Loshitsky, 1999; Hansen, 2000).

Los cineastas producen historia en formatos que tienen un valor estético y donde las narrativas se organizan de acuerdo a principios dramáticos y no cronológicos (Ferro y Planchais, 1997). Al escribir memorias con la cámara de cine, los hechos ocurridos son editados, condensados, y a menudo modificados (Rosentone, 2000). Pero el hecho de que los filmes recreen el pasado ficcionalmente no minimiza su función como "contadores de historias". No podemos ignorar la producción fílmica sobre la dictadura y su influencia sobre el conocimiento de este pasado. En otro lugar, analicé cómo, para una generación de jóvenes de Buenos Aires, el filme La noche 
de los lápices (Héctor Olivera, 1986) se convirtió en una de las principales fuentes de información sobre la dictadura (Kaiser, 2005). ${ }^{5}$ Cabe aclarar que en el caso de Argentina, no siempre es fácil catalogar los filmes sobre este período histórico ya que es un tema recurrente, directa o tangencialmente. Está presente en muchos filmes contemporáneos y parecería estar entretejido en la producción cultural de la posdictadura (ibid.). ${ }^{6}$

\section{Lo que nos contó el cine argentino sobre la dictadura}

Al finalizar la dictadura, el cine argentino emergió de lo que Getino (2005: 70) llama su "noche". Como nota Varea (2006), el cine producido durante la dictadura se caracterizó por auto-censura, chatura, vacíos, promoción de orden y valores cristianos, admiración por las instituciones políticas, y sexo velado. Varios directores, productores y actores se beneficiaron, colaboraron, o pusieron su cara y sus filmes para promover una buena imagen de Argentina en el exterior y contrarrestar las campañas "antiargentinas" denunciadas por las Juntas militares. La represión también golpeó fuerte a la industria. Muchos cineastas debieron exiliarse y se estima que dos directores, veintiún actores y un productor desaparecieron (Jakubowicz y Radetich, 2006: 138). ${ }^{7}$

Para Aguilar (2006: 137), el cine argentino que acompañó el proceso de democratización se dedicó a concientizar. Los filmes transmitían un mensaje al espectador y las historias daban prioridad a esclarecer los hechos recientes. Coincidiendo, Getino (2005: 98) nota que de aproximadamente 130 filmes que se estrenaron entre 1984 y 1988, aquellos relacionados con la dictadura tienden a denunciar lo que pasó, o lo que "los otros" hicieron, una postura que resulta en una falta de análisis crítico sobre este pasado, en particular sobre el papel jugado por la sociedad.

En general, los filmes que exploran el terrorismo de Estado no han atraído grandes audiencias. Solo puedo conjeturar sobre las razones pero coincido con Koza (2004: 62-63) cuando, refiriéndose a Kamchatka, se pregunta cuál es la cuota de realidad que el público argentino es capaz de tolerar. De las veinte películas más taquilleras del período 1984-2004, La historia oficial (1985) es la única que trata directamente sobre la dictadura y ocupa el puesto número cuatro. Camila (1984), el filme de Maria Luisa Bemberg que discute esa época metafóricamente, ocupa el segundo puesto (Getino, 2005: 365).

\footnotetext{
${ }_{5}^{5}$ Ver capítulos 8 y 9 . En una encuesta conducida por profesores de la Universidad de Buenos Aires, $74.7 \%$ de los 500 estudiantes universitarios encuestados dijeron haber aprendido sobre la dictadura por este filme (Ranalletti, 1999: 14).

${ }^{6}$ Ver capítulo 8.

${ }^{7}$ Los directores son Raymundo Gleyzer y Pablo Szir.
} 
Hay dos filmes que se convirtieron en los clásicos sobre esta temática. El primero fue La historia oficial (Luis Puenzo, 1985), ganadora del Oscar 1986 a la mejor película extranjera. Trata del robo de bebés nacidos en cautiverio y cuyas madres eran luego desaparecidas. La narrativa central gira en torno a una profesora de historia cuyo marido empresario colabora con la dictadura y su toma de conciencia sobre lo que ha estado pasando en el país al descubrir que la hija que adoptaron es hija de desaparecidos. Se hace referencia al papel de los civiles pero algunas críticas señalan que la representación de una sociedad ignorante resulta en un filme para que la clase media se sienta bien y sirve para calmar remordimientos de quienes no hicieron nada para detener el terror. ${ }^{8}$ Refleja bien el contexto del principio del retorno a la democracia, "aquel tiempo en que todos éramos víctimas, niños inocentes aterrorizados por el régimen militar” (Depetris Chauvin, 2006: 104).

La noche de los lápices (Héctor Olivera, 1986), ya mencionada, recrea hechos reales que se han convertido en el símbolo de la represión a los jóvenes: el secuestro, tortura y desaparición de un grupo de estudiantes militantes. Basado en el libro de un sobreviviente, transmite de manera gráfica los métodos que utilizó la dictadura para eliminar disidentes políticos - patotas armadas irrumpiendo en las casas en medio de la noche, torturas, violaciones, asesinatos. Fue el primero en mostrar escenas de torturas brutales. Si bien era importante representar el nivel de los crímenes, este show del horror sería criticado por el potencial de actuar como elemento paralizador, una advertencia a los jóvenes de lo que les puede pasar si se meten en política. ${ }^{9}$

En los años siguientes, hubo muchos filmes sobre la dictadura. Es particularmente rica la producción de documentales que tocaron temas ignorados o minimizados por el cine narrativo. Una variedad de producciones asumieron la responsabilidad de enfocarse en ese pasado (Aguilar, 2006: 175; Jacubowicz y Radetich, 2006: 23, 26). Los temas tratados incluyeron: casos específicos de represión, testimonios de militantes en organizaciones políticas y grupos guerrilleros, perfiles de personajes relevantes de la época, el trabajo de las organizaciones de derechos humanos, las secuelas del terrorismo de Estado a nivel político, social y económico. Debemos incluir aquí filmes dirigidos por cineastas que son hijos de desaparecidos..$^{10} \mathrm{La}$ distribución y repercusión de estos documentales no es pareja. Algunos tuvieron

\footnotetext{
8 Ver capítulo 8 en Kaiser (2005).

9 Ver capítulo 9 en Kaiser (2005).

${ }^{10}$ En otro lugar (Kaiser, 2007), analizé estas producciones y lo que las miradas de las/los hijas/os han aportado a la construcción de memorias de la dictadura.
} 
circulación reducida en festivales regionales, otros ganaron premios internacionales, se estrenaron en el país y el extranjero, y es fácil conseguir los DVD. Importa resaltar que hay suficientes filmes como para explorar la dictadura exclusivamente a través de documentales. La producción sigue, lo que sugiere que las memorias de esos años continuarán siendo bien representadas por este género. ${ }^{11}$

En cuanto al cine de ficción, que es lo que nos interesa aquí, podemos identificar una serie de temas recurrentes. Respecto a representaciones de la represión y el horror, uno de los filmes más analizados es Garage Olimpo (1999) cuyo director, Marco Bechis, sobrevivió a su desaparición. Es la historia de una joven activista secuestrada y los días que pasa en un centro de tortura, incluyendo la problemática relación con su torturador, hasta que es arrojada al mar en un vuelo de la muerte. La vida dentro del espacio claustrofóbico del centro es contrastada con la aparente normalidad de la vida afuera del mismo (Molas y Molas y Bersotti, 2006: 24-25). El exilio, tanto externo como interno, y el retorno o "desexilio", afectó a millares de personas. Varios filmes hacen referencias marginales al tiempo en que se vivió en otro país, encuentros con amigos que están de vuelta, o familias dispersas por varios lugares. Pino Solanas dirigió dos filmes que tocan el tema directamente: Tangos, El exilio de Gardel (1985) y Sur (1988), que se enfoca en un sector generalmente ignorado: la clase obrera. El tema de la complicidad civil apenas ha sido tocado. Sobresale un filme considerado por Getino (2005: 127) como "uno de los estudios más auténticos y rigurosos sobre el tema de los desaparecidos". Un muro de silencio - dirigida por Lita Stantic, 1993 - contradice la noción de la ignorancia generalizada y desafía al espectador a cuestionar la responsabilidad de la sociedad. Inspirada en la historia de la directora - el padre de su hija desapareció - la última escena es de madre e hija visitando las ruinas de un ex centro de tortura. Cuando la hija pregunta si la gente no sabía, la madre le responde "todos sabían".

Como ya señalé, el tema de los niños robados fue tratado en La bistoria oficial y lo discutiré al analizar Cautiva. ${ }^{12}$ Pero quiero mencionar un filme que se animó a plantear una situación desde una perspectiva perturbadora y audaz. Vidas privadas (Fito Páez, 2001) relata la historia de una mujer que sobrevivió a su desaparición y se exilió en España. Estando desaparecida tuvo un hijo que le robaron. Cuando vuelve a Argentina a visitar a su

${ }_{11}$ Para trabajos recientes analizando la producción de documentales ver Sartora y Rival, 2007; Verzero, 2009.

${ }_{12}$ Otros filmes importantes sobre este tema son Hijos (Marco Bechis, 2001) y Buenos Aires viceversa (Alejandro Agresti, 1996). 
padre enfermo inicia una relación con un "taxi boy" que se convierte en una pesadilla de fantasías edípicas e incestuosas. Aunque podamos dudar de que el joven sea su hijo, el filme muestra la perversidad de una de las posibles consecuencias de privar a cientos de gente de su identidad. Esos bebés robados, ahora adultos, no tienen idea de quiénes pueden ser sus hermanos, madre, padre, tíos. En cuanto a la guerra de Malvinas (1982), la última locura bélica del terrorismo de Estado, los filmes han representado la crueldad de las autoridades militares y los abusos contra los jóvenes soldados, algo que no siempre se incluye entre los crímenes cometidos por la dictadura. Se destacan Los chicos de la guerra (Bebe Kamín, 1984) e Iluminados por el fuego (Tristán Bauer, 2005).

Esta breve sinopsis de lo que nos contó el cine argentino sobre la dictadura ha dejado mucho sin cubrir, por ejemplo, la mención a las escasas películas sobre las consecuencias económico-sociales de la misma. ${ }^{13}$ Pero nos da una idea de lo que ya se ha dicho y de lo mucho que falta por decir.

\section{Cuatro filmes que abordan asignaturas pendientes}

Analizo aquí cuatro producciones recientes: Kamchatka, Cautiva, Hermanas y Crónica de una fuga. Los directores de estos filmes incluyen miembros de la generación que fue testigo del terror y también de una nueva generación de cineastas que eran niños durante esa época. Los filmes presentan nuevas perspectivas sobre temas tales como el funcionamiento del aparato represivo, el horror de la vida dentro de los centros de tortura y exterminio, el robo de bebés nacidos en cautiverio. También exploran con más profundidad temas con los cuales la sociedad argentina todavía tiene asignaturas pendientes: indiferencia, complicidad y culpa de los civiles, debilidades y delaciones, resistencia y solidaridad, cómo reaccionaron ciertos sectores de la sociedad frente al miedo y a los peligros de la represión sufrida por familiares, amigos y conocidos.

Me interesan en particular las representaciones ficcionales de la responsabilidad de los civiles, una discusión que en la Argentina apenas ha empezado. Podríamos hablar de un proceso generalizado de auto-engaño que hace difícil mirar hacia atrás con honestidad y reconocer qué se hizo y qué no se hizo durante esa época. Es más fácil recordar aspectos positivos del pasado, pensar que actuamos bien, y convencernos de que nunca estuvimos del lado de "los malos". Baumeister y Hastings (1997) argumentan que para

\footnotetext{
${ }_{13}$ Ver el capítulo 7 en López y Rodriguez (2009), en particular el análisis de los filmes de ficción Plata dulce (Fernando Ayala, 1982) y La deuda interna (Miguel Pereira, 1987), y del documental Memoria del saqueo (Pino Solanas, 2003).
} 
defender una auto-imagen positiva, individuos y grupos sociales desarrollan mecanismos para enfrentarse a pasados poco gratos, revisando el significado de los eventos y distorsionando sus memorias de manera sistemática. Estos mecanismos de distorsión incluyen: editar las causas de los hechos con omisiones e inventos, contar el lado de la historia que beneficia mejor ciertos intereses, o culpar a la víctima por la suerte corrida. El argumentar que no se sabía lo que pasaba, por ejemplo, es una distorsión. ${ }^{14}$ Como nota Manzano (2009: 176) en su análisis de Garage Olimpo, los ojos vendados de los prisioneros son una metáfora de una sociedad auto-vendada que no quiso ver en los setenta y no quiere ver en los noventa. A conclusiones similares llegué en mi estudio sobre las posmemorias de la dictadura en jóvenes porteños, muchos de los cuales no cuestionaban la idea de que la gente "no sabía". ${ }^{15}$

Toda representación está recreando. Al reconstruir el pasado, los filmes pueden editarlo para servir los intereses del presente. Esta podría ser una lectura sobre la sociedad ignorante representada en La historia oficial. Hay patrones generacionales de auto-engaño. Cada nueva generación tiene ciertos valores y cuando los jóvenes analizan las acciones de sus mayores en un nuevo contexto, pueden distorsionar sus memorias para que concuerden con sus valores (Baumeister y Hastings, 1997). Importa considerar estos procesos al analizar las producciones de realizadores jóvenes que quizás cuestionen las versiones de la dictadura que recibieron.

30000 personas no desaparecen porque un grupo de militares crueles decide tomar el poder. El terrorismo de Estado y las violaciones masivas a los derechos humanos necesitan del apoyo de la población civil, ya sea por colaboración directa o indiferencia cómplice. Amplios sectores de la sociedad colaboraron con - y se beneficiaron de - la dictadura militar. ${ }^{16}$ Pilar Calveiro (1998), quien sobrevivió su desaparición, explica convincentemente que los campos de tortura y exterminio no pueden verse como aberraciones aisladas sino que hay un papel jugado por la sociedad en relación al poder desaparecedor de la dictadura. Pavlovsky (1999) observa que los sectores indiferentes e ignorantes funcionaban como "un gran colchón social acrítico". Obviamente, hay diferencias entre culpabilidad y responsabilidad. Pero como dice Habermas (1994: 7) respecto a la sociedad alemana del Nazismo, existe la responsabilidad colectiva por el contexto mental y cultural en que los crímenes masivos

\footnotetext{
${ }^{14}$ Según el Nunca Más, el informe de la CONADEP, la mayoría de los desaparecidos fueron secuestrados frente a testigos.

${ }_{15}$ Ver capítulo 4 en Kaiser (2005).

16 Para un análisis de los sectores cuyo apoyo fue clave para la dictadura, ver Verbitsky (1997).
} 
son posibles. De varios individuos se podría decir lo que subrayara Hannah Arendt (2004: 97) en la sentencia del juicio a Eichman, que el grado de responsabilidad aumenta a medida que nos alejamos del hombre que usa con sus propias manos el instrumento fatal.

Varios filmes han mostrado a torturadores y asesinos, pero no han sido frecuentes las referencias a los responsables, a los que están "alejados" del que aplica la picana eléctrica o tira prisioneros al mar pero tienen también las manos manchadas de sangre. Los cineastas que se han comprometido a narrar con más detalles este pasado son críticos de las deudas que el cine tiene con la sociedad. Lita Stantic (en Soto, 2006) señala que hay muchos filmes de ficción que concentran la maldad en los militares y no muestran a la gente que respaldó y aplaudió su llegada, o a la colaboración prestada por los grandes grupos económicos y los empresarios. Según Schwarzböck, "lo que en la Argentina estaba sucediendo en 1977 lo juzgamos hoy más por lo que entonces sucedía adentro de un campo de concentración que por todo lo que sucedía afuera de él" (2007: 66, énfasis en el original). Es sobre este afuera del que todavía hay mucho por contar. Como veremos en lo que sigue, otras historias están siendo narradas, otras memorias están siendo reconstruidas y transmitidas, y algunas de estas omisiones están ahora presentes en ciertas producciones.

\section{KAMCHATKA (2002) - El círculo se cierra}

Kamchatka, dirigida por Marcelo Piñeiro, explora el terrorismo de Estado a través de la mirada de un niño de diez años. La historia transcurre en 1976 durante los primeros tiempos de la dictadura, cuando los secuestros, asesinatos y desapariciones escalaron en intensidad. Los temas centrales son el miedo, la angustia, la vulnerabilidad, la incertidumbre, el aislamiento, sobrevivir y escapar. Una pareja de clase media, ella es una investigadora científica y él un abogado, se ve forzada a pasar a la clandestinidad luego de que el socio de él es secuestrado. La pareja y sus dos hijos - el más pequeño tiene cinco años - dejan todo y se esconden en una casa que les prestaron en los alrededores de Buenos Aires. Los padres explican a sus hijos que hay problemas y que van a tomarse unas vacaciones hasta que se calme la situación. El filme muestra a la familia viviendo clandestinamente, cambiándose los nombres y sus historias, inventando nuevas ocupaciones para los padres, así como el proceso de enseñar a los niños a responder a preguntas de acuerdo a sus nuevas identidades, advirtiéndoles que no hagan llamadas o contesten el teléfono, prohibiéndoles que vean a sus amigos, enseñándoles cómo adaptarse a la nueva escuela, entrenándolos para que sepan esconderse y también escapar en minutos si alguno de los padres advierte 
“zafarrancho". El círculo va cerrándose y al sentirse acorralados y sin salida, los padres deciden no arriesgar más a los niños. Los dejan con sus abuelos y continúan escapando.

A pesar de que no hay ninguna escena de violencia, la presencia de lo atroz está impregnada en todo el filme. A quienes vivimos en Argentina durante aquellos años nos resulta fácil entender por lo que pasa la familia. No hay lugares seguros, amigos y conocidos continúan desapareciendo, circulan rumores sobre las atrocidades que se están cometiendo, hay que desconfiar de todo y de todos, la gente se aísla de quienes percibe pueden ser peligrosos, se cierran puertas pero ninguna se abre, es fuerte la sensación de que los pasos detrás nuestro se van acercando y ya no hay ningún lugar donde buscar refugio.

A pesar del terror, los padres se esfuerzan para mantener una sensación de aparente normalidad en la vida cotidiana. Están decididos a enfrentar unidos la incertidumbre, proteger a sus hijos, y preservar su niñez. Escuchan música, cantan, bailan, cocinan y saborean comidas deliciosas. El niño mayor adopta el nombre Harry porque está fascinado con un libro sobre el escapista Houdini que ha encontrado en la casa donde están escondidos. Harry juega con su padre a T.E.G. (Tácticas y Estrategias de Guerra). En ese juego, el ultimo bastión es Kamchatka, de ahí el nombre del filme. Kamchatka se convierte en una metáfora de la resistencia, un espacio desde el cual se pueden juntar fuerzas y enfrentar al terror. La última escena es el auto de los padres alejándose por un camino rural mientras el hijo mayor los ve perderse en el horizonte y su voz en off dice: "La última vez que vi a mi padre me contó de Kamchatka. Y esa vez entendí. Y cada vez que jugué mi padre estuvo conmigo. Cuando el juego no iba bien, me quedé y sobreviví. Porque Kamchatka es el lugar desde donde resistir". Esto confirma que los padres desaparecieron y nos plantea la angustia de los niños sobreviviendo a un trauma de tal magnitud.

El filme muestra a la familia escapándose y describe en detalle cómo el círculo de seguridad se va cerrando aceleradamente. El sentimiento de estar acorralados es asfixiante y abrumador. Vemos a la familia andando en su auto sin rumbo fijo, esperando mientras el padre hace llamada tras llamada desde teléfonos públicos, o sentados en un parque mientras anochece y sin haber encontrado un lugar para esconderse. No hacen falta muchas palabras para entender que el padre va recibiendo información sobre conocidos que han sido secuestrados, que le dicen que no puede ir a ciertas casas, que ya no queda nadie que les pueda ofrecer un refugio seguro. Estas puertas que se cierran hablan de una falta de solidaridad que puede explicarse por el miedo que sentía la gente. Pero también nos recuerdan a los muchos que 
ignoraron lo que estaba pasando delante de sus ojos, la sociedad vendada que hemos mencionado.

Contrastando el aislamiento al que se ve forzada la familia, el filme también resalta solidaridades. Alguien les presta una casa. Esto es algo que muchísima gente hizo, esconder personas por una noche o unos pocos días, incluso por unas horas, prestando casas, refugiando a gente a la que nunca habían visto antes y quizás nunca volverían a ver. Como cuenta el escritor y poeta uruguayo Mario Benedetti, cuando vivía exiliado en Buenos Aires durante el terror llevaba cinco llaves ajenas, de cinco casas, de cinco amigos. Esas llaves lo salvaron. ${ }^{17}$

Harry va descubriendo la realidad del terrorismo de Estado en base a lo que escucha que sus padres comentan. Otros filmes recientes también han elegido representar la violencia política en Latinoamérica a través de los ojos de los niños - Voces inocentes (Luis Mandoki, Mexico, 2004), sobre la guerra civil en El Salvador; Machuca (Andrés Wood, Chile, 2004), acerca del golpe que derrocó a Allende; $O$ ano em que meus pais saíram de férias (Brazil, Cao Hamburger, 2006), sobre la dictadura brasilera. Estos filmes sugieren que hay cineastas interesados en explorar y exponer los que los niños sufrieron en esos procesos. Esto ayuda a entender las secuelas de la violencia política en una generación que creció durante el terror y cómo sus memorias pueden influir en cómo piensan y actúan ahora que son adultos. Estos filmes tratan sobre niños directamente afectados. Otro tema pendiente sería explorar cómo los niños de esa generación que aparentemente no fueron afectados, por ejemplo chicos argentinos cuyos padres no fueron perseguidos, reaccionaron frente a la represión experimentada por amigos y compañeros, y cómo han ido procesado esta información a través de los años.

Se ha dicho que Kamchatka es un producto de la industria cultural global que idealiza un pasado de buenos y malos, presenta una visión despolitizada de la sociedad, y no estimula lecturas críticas (Tal, 2005). Cómo leemos e interpretamos un texto está influenciado por lo que sabemos sobre el tema y cuáles son nuestras experiencias en relación al mismo. Desde mi punto de vista, quizás el filme está dirigido a un público local (argentino) que puede darle significados que el espectador global no puede.

\section{CAUTIVA (2003) - El torturador [No] es un buen padre}

Cautiva, dirigida por Gastón Birabén, cuenta la historia de una jovencita de quince años que en 1994, a más de una década de finalizada la dictadura, debe presentarse ante un juez que le informa que es hija de desaparecidos

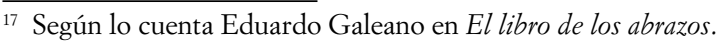


y que su abuela biológica la ha estado buscando por años. Quienes la criaron, un policía de alto rango y su mujer, son sus apropiadores. Su madre biológica la llamó Sofía, los que la robaron, Cristina. El filme cuenta el proceso por el cual Sofía descubre las mentiras en las que creció, la verdadera historia de los que pretendieron pasar por sus padres y fueron cómplices en la desaparición de sus verdaderos padres, su shock y confusión frente a lo que va descubriendo, la búsqueda de su identidad, el inicio de relaciones con su familia biológica (abuela, tía, tío y primos), su creciente interés en enterarse de lo que sucedió durante el terror, y su cruzada para averiguar la suerte corrida por sus padres.

$\mathrm{Al}$ robo de bebes como botín de guerra se lo define como "apropiación" para marcar las diferencias con "adopción" ${ }^{18}$ Se estima que 500 bebés fueron apropiados. Como comentara un vecino de un barrio de oficiales navales, "los bebés se regalaban como gatitos" (en Kollman, 2004). El foco del activismo inclaudicable de las Abuelas de Plaza de Mayo es encontrarlos. A fines de 2009 ya habían recuperado 100 nietos. Cautiva muestra con precisión cómo funcionaba el sistema, incluyendo las múltiples colaboraciones implicadas en este proceso: familias de militares o de quienes los apoyaban, la perversidad de los supuestos padres criando a los hijos de hombres y mujeres con cuyas torturas y desapariciones colaboraron, torturadores y asesinos coordinando el robo y distribución de bebés, la complicidad de médicos, parteras y enfermeras aterrorizadas a las que no se les permitía hablar con las prisioneras, las condiciones inhumanas en que daban a luz, la falsificación de certificados de nacimiento. También vemos que las familias biológicas nunca abandonaron la búsqueda y que aquellos que se animan a hablar sobre los horrores de que fueron testigos contribuyen a devolver la identidad a los bebés robados. ${ }^{19}$

Sofía fue traída por el mejor amigo de su "padre", un torturador infame al que ella llama cariñosamente "tío Jorge". Ha crecido en un hogar donde la dictadura se conoce como "la guerra contra los comunistas". Es a través de una compañera de escuela, hija de desaparecidos, que descubre cómo operaba el terrorismo de Estado. Esta compañera la ayuda en la búsqueda, conectándola con grupos de derechos humanos, y organizando un encuentro con una enfermera que participó en el parto y que después de 16 años, se anima a romper el silencio. La película muestra la solidaridad entres los hijos de desaparecidos y cómo las historias se van armando a través de las

${ }_{18}$ Es un crimen que no fue contemplado en las leyes de impunidad y la búsqueda y persecución de culpables nunca ha cesado.

19 Para un estudio excelente sobre la apropiación de niños y la lucha de las Abuelas de Plaza de Mao ver Arditti (1999). 
pequeñas piezas de información obtenidas por diferentes fuentes. Las referencias a organizaciones de derechos humanos incluyen escenas de marchas de Madres y Abuelas, y el encuentro con la enfermera que asistió en el parto se realiza en el local donde se reúnen habitualmente los miembros de la organización H.I.J.O.S.

A Sofia la llevan del colegio a la oficina del juez sin permitirle que avise a sus "padres". El juez ya conoce su identidad real a través de una prueba de ADN hecha sin su conocimiento durante un examen para una operación de apendicitis. Se evitó poner en guardia a los apropiadores para que no abandonaran el país llevándosela, algo que sucedió en algunos casos. Ha habido debates respecto a obligar a una prueba de ADN. Algunos jóvenes se han negado a hacérsela y las Abuelas de Plaza de Mayo se oponen a realizarlas mediante engaños. Hay quienes opinan que las familias biológicas tienen derecho a exigirla para conocer la verdad que se les debe a los familiares y a la sociedad. ${ }^{20}$

Quienes critican los esfuerzos de las Abuelas por recuperar sus nietos suelen argumentar que es mejor dejar a los jóvenes con las familias que los criaron para así evitarles otro trauma. ${ }^{21}$ Además de considerar esos casos como si fueran adopciones regulares, esas críticas ignoran lo que ha pasado con los nietos recuperados (ahora en sus treinta). Con pocas excepciones, han establecido buenas relaciones con sus familias biológicas. En los casos de adopciones por quienes ignoraban el origen de esos bebés, los nietos mantienen relaciones con las familias adoptiva y biológica. En la mayoría de los casos de apropiación por familias militares y sus cómplices los jóvenes han cortado los vínculos con sus apropiadores, la situación representada en Cautiva. Una desafiante Sofia enfrenta a sus "padres" y les echa en cara sus mentiras diciéndoles que sabe todo: el alias del "tío/torturador" que la trajo, el nombre de sus verdaderos padres, a qué se dedicaban, donde estuvieron secuestrados, las condiciones en que su madre la tuvo, y cómo la hicieron desaparecer después del parto. Incluso le pregunta a su "padre" policía si conoció, torturó y mató a sus padres biológicos. Su "madre" insiste en que no sabía esos detalles pero Sofía la acusa de complicidad. Una de las últimas cosas que le dice antes de irse es "no querías saber". Se denuncia la pretendida ignorancia detrás de la que se escudan muchos responsables.

Las escenas en el colegio de Sofía ilustran cómo se transmiten ciertas ideologías y la coexistencia de varias comunidades mnemónicas. La hija de

\footnotetext{
${ }^{20}$ A partir de 2009, nuevas leyes obligan a la prueba a quienes se sospeche puedan ser hijos apropiados. Se puede hacer por métodos alternativos con material obtenido de artículos personales como peines o ropa requisados de los domicilios mediante orden judicial.

${ }^{21}$ Ver capítulo 5 en Kaiser (2005).
} 
desaparecidos desafía a la profesora preguntándole sobre la dictadura; otra estudiante alega que sus padres no están desaparecidos sino en Europa, algo que las autoridades militares solían decir a quienes buscaban a sus familiares. Hay una recreación del nacimiento de Sofía, su madre con marcas de tortura, los ojos vendados y las manos atadas, que muestra la solidaridad de la enfermera que se arriesga a apuntar los nombres de la madre y su esposo, lo que le permitió ayudar a Sofía a poner juntas las piezas del rompecabezas.

Cautiva fue reconocida en festivales internacionales y elogiada por organizaciones de derechos humanos, incluyendo Abuelas e H.I.J.O.S. Pero estuvo poco en cartelera (Bellon, 2005). Una sicóloga que trabaja en la Comisión Nacional por el Derecho a la Identidad (CONADI), considera que la película ignoró a las Abuelas de Plaza de Mayo y no hay una presencia de la organización a pesar del papel central que jugó, algo problemático porque la identidad no es solo individual sino también social y familiar (Gorodischer, 2005). Sin duda, estas son observaciones válidas pero es muy difícil cubrir todos los aspectos de un tema tan complejo. Es común exigir de los cineastas comprometidos que sus producciones nos entreguen versiones perfectas del tema que representan. Cautiva presenta facetas de esta temática como ningún filme de ficción lo había hecho, especialmente los detalles de cómo operaba el macabro sistema en todos los niveles y las grietas que permitieron aportar datos para que los jóvenes apropiados recuperen su identidad. Esto último es importante porque la búsqueda continúa y cuanta más gente cuente lo que sabe hay más posibilidades de recuperar nietos.

\section{HERMANAS (2004) - Acerca de silencios, culpas y verdades}

Hermanas, dirigida por Julia Solomonoff, es la historia de dos hermanas que no se han visto por ocho años y se reencuentran en Texas en 1984. Elena, su esposo y el hijo de ambos de ocho años se acaban de mudar a Texas. Natalia vive en España. Se fue de Argentina durante la dictadura luego de que su novio Martín desapareciera. Al morir, el padre de ellas dejó una novela sin publicar. Elena trajo el manuscrito con ella. Natalia comienza a leerla y se da cuenta de que relata la historia de su familia durante la represión. Son los tiempos de la vuelta a la democracia y varios exiliados están regresando a Argentina. Natalia todavía tiene miedo de volver pero quiere enterarse de quién más sabía dónde se estaba escondiendo su novio la noche que fue secuestrado, y quién lo denunció. Mediante flashbacks a los tiempos previos a la desaparición de Martín, la película cuenta la historia de las hermanas, incluyendo las relaciones entre ellas, con sus padres y con sus novios, el entorno político de esos tiempos, y el activismo juvenil. Falta la 
última página del manuscrito que una culpable Elena ha arrancado y finalmente entrega a Natalia confesándole que fue ella quien delató el escondite de Martín.

$\mathrm{Al}$ enfocarse en dos hermanas muy distintas, la película nos presenta un mosaico de la sociedad argentina durante el terror y muestra cómo, a pesar del amor y vínculos familiares sólidos, y mediante miedos, silencios, mentiras, desconfianzas, complicidades y traiciones, la represión invadió las esferas privadas y afectó todo tipo de relaciones. Al mostrar cómo las hermanas fueron afectadas por el terror, el filme explora cómo la sociedad en general fue devastada. Tomando a la familia como metáfora, se exploran silencios sociales, el legado de los miedos, y la vulnerabilidad de una sociedad quebrada por el terror y la represión. Como afirma Solomonoff: "No planteé una lucha entre una hermana buena y otra mala; va más allá: se jodieron todos" (en Respighi, 2005).

Ideológicamente, hay grandes diferencias entre las hermanas. Elena y su marido representan a esos sectores de la sociedad que apoyaron la dictadura, o al menos la toleraron y adoptaron su discurso, y se lo han transmitido a su hijo que creció durante el terror. El niño dice cosas tales como: "mi abuelo era comunista y estuvo en Cuba pero eso no se lo tenemos que decir a nadie". Ese comentario refleja el miedo que sus padres quienes conscientes del nivel de la represión, entrenaban a su hijo para que no los comprometiera - comparable con las instrucciones a los niños de Kamchatka. En otra ocasión, furioso porque su tía quema el popcorn que está preparando, le dice: "Vas a quemar mi casa, andáte. Ya sabía que eras una terrorista y una Montonera". Aquí hay una asimilación del discurso de que todos los activistas eran terroristas y que, aparentemente, es lo que sus padres piensan de la tía que se exilió. Podemos comparar este comentario con el de las compañeras de colegio de Sofía en Cautiva, memorias que se transmiten intergeneracionalmente, niños y adolescentes repitiendo lo que escuchan en sus casas.

La culpa que siente Elena y la angustia que le produce son evidentes en su malhumor, pesadillas, e irritabilidad. Natalia le trajo de vuelta un ayer que intentó olvidar. Elena está borrando memorias. Natalia quiere recordar y buscar la verdad. Este descubrir la verdad es el primer paso hacia la justicia. Se plantean las razones y los niveles de traición. Natalia llega a preguntarse si no habrá sido su padre el que delató a Martín, de quien era su mentor y cuyo escondite conocía. El día que su novio desapareció la policía fue a la casa de Natalia y, como no la encontraron a ella, se llevaron a su padre a la comisaría. Por eso piensa que quizás lo torturaron y sus sospechas incluyen la posibilidad de que su padre haya contado lo que sabía. 
Morini, el tío del marido de Elena y director del colegio católico al cual Martín había asistido, representa la complicidad de las autoridades civiles y la jerarquía Católica. La novela menciona a alguien del colegio que colaboraba con los militares. Cuando el padre fue llevado preso, Morini, que tenía buenas conexiones con la policía, le ofrece ayuda a Elena asegurándole que si Martín se entrega arrepentido no le sucederá nada. También le dice que si su padre es acusado de estar implicado en el caso no será liberado y si lo torturan, es probable que su corazón no resista. Pretendiendo ser un buen amigo de la familia le exige a una adolescente aterrada que asuma su responsabilidad por la posible tortura y muerte de su padre. Una forma de tortura sicológica, una manera sutil de decir: hablá, delatá o torturaremos y mataremos a tu padre. Cuando Elena le entrega a su hermana la página le dice: "No quería que supieras nada. Papá estaba preso y Morini me aseguró que nada le iba a pasar a Martín. Yo fui la que dijo donde estaba." El filme plantea una situación que no fue única. Familiares angustiados a los que un pariente, amigo o conocido de confianza les sacó información para entregársela a los represores. Basta recordar a Graselli, capellán de la armada, quien recibía a los familiares de desaparecidos y utilizaba la información que le daban para actualizar su "archivo" que incluía listas donde marcaba con una cruz los que ya estaban confirmados como muertos.

Hermanas trata sobre los años de plomo y la acción transcurre en 1984, al comienzo del gobierno democrático. Pero el filme fue producido en 2004. El momento para discutir más a fondo ciertos temas tardó dos décadas en llegar. Hay una distancia que permite explorar nuevas perspectivas por una cineasta que era una niña durante la dictadura y una adolescente en la época en que transcurre el filme. Según Solomonoff, el filme pregunta "qué les pasó a los que intentaron continuar con sus vidas como si nada en medio del horror" (en Tessa, 2005). Para ella, no se trata de hablar de la dictadura sino de romper pactos de silencio y hablar sobre donde están hoy las personas que fueron instrumentales en generar traición y muerte (en Garcia, 2004). Dice que escribió el guión en respuesta a las preguntas: ¿Qué me hubiera pasado a mí si hubiera nacido diez años antes? ¿Estaría desaparecida o exiliada? ¿Cómo manejaría el peso de ser una sobreviviente? Según sus palabras: "Hermanas no es un filme sobre los militares sino sobre los civiles, y sobre las conspiraciones de silencios que nos convierten en víctimas y cómplices" (Hermanas DVD, Notas de la directora). Su filme efectivamente cuestiona el papel jugado por la sociedad civil, y sugiere que hay un examen de conciencia, todavía pendiente, en que cada argentino que vivió esa época debería plantearse 
con honestidad qué hizo y qué no hizo, y porqué actuó de esa manera. Al tratar temas de los que se habla muy poco Hermanas contribuye a alentar debates sobre la complicidad civil.

\section{CRONICA DE UNA FUGA (2006) - El horror del "Chupadero"}

Crónica de una fuga está dirigida por Israel Adrián Caetano, un reconocido director del llamado "nuevo cine argentino" que nació en Uruguay y se fue a vivir a la Argentina siendo adolescente. Está basada en el libro de Claudio Tamburrini, Pase libre: la fuga de la Mansión Seré, donde describe las experiencias que vivió como desaparecido hasta que consiguió escaparse junto con otros tres prisioneros del centro clandestino donde estaban secuestrados. Comienza con el secuestro de Claudio, estudiante de filosofía $\mathrm{y}$ arquero de fútbol del club Almagro, quien fue delatado por un conocido. El filme muestra cómo un grupo de tareas lo "chupa" (secuestrar en la jerga de la represión) y narra los 120 días que pasó desaparecido hasta su fuga el 24 de marzo de 1978, fecha del segundo aniversario del golpe militar. La mayor parte del filme transcurre dentro de la Mansión Seré, originalmente la residencia de una familia de la aristocracia que la Fuerza Aérea utilizó como centro de tortura o "chupadero" de la dictadura (lugar donde se tenía a los "chupados").

Caetano tiene un estilo para representar el horror que evita saturar la pantalla con representaciones gráficas de violencia que puedan espantar al público. Nunca vemos una picana eléctrica y solo la cara del torturador cuando la aplica. Hay una sola escena explícita de tortura - el "submarino" (hundir al prisionero bajo agua hasta casi ahogarlo). También hay un simulacro de ejecución y se muestra el brutal tratamiento diario, una combinación de golpes e insultos cuando los prisioneros son alimentados o llevados de una habitación a la otra. Caetano dice que no quiere mostrar ciertas cosas y que no tiene sentido mostrar solamente el horror (en Blejman, 2006). Según él, el tratamiento de este tema en el cine de los ochenta se basó en mostrar tortura y más tortura, lo que resultó en filmes donde los torturadores son más importantes que sus víctimas (en Kairuz, 2006).

$\mathrm{El}$ director se las ingenia para colocar al espectador en el lugar del prisionero. Desde diferentes ángulos, vemos fragmentos de los torturadores, lo que verían los prisioneros si no tuvieran los ojos vendados - por ejemplo, estando tirado en el piso con una bota que le patea brutalmente la cabeza. En vez de mirar escenas de tortura, vemos a los torturadores desde la mirada de la víctima. La cámara los enfoca y muestra en detalle sus apariencias físicas, su sadismo, cómo hablan y se mueven, cómo interactúan entre ellos, y las rutinas y procedimientos dentro del centro de tortura. Los espectadores, 
al igual que los prisioneros en la Mansión Seré, no tenemos ni idea de lo que va a suceder al minuto siguiente. Empapados de miedo, sentimos el terror de la incertidumbre. En base al conocimiento sobre la represión que hemos adquirido a través de los años nos podemos imaginar lo que les pasa, que las horribles marcas de tortura en sus cuerpos (moretones, piel quemada) nos confirman. Estamos invitados a llenar los espacios en blanco, dependiendo de lo que sabemos sobre lo sucedido. Las marcas en los cuerpos de los prisioneros son como las que dejó la dictadura: evidentes. $\mathrm{Y}$ en esas evidencias documentadas se fundan las causas judiciales.

Crónica se anima a tratar el tema de la delación. La primera secuencia es un prisionero marcándole la casa de Claudio a la patota que lo tiene secuestrado. Bajo tortura, los prisioneros han "cantado" nombres para ganar tiempo y permitir que militantes asociados con ellos escaparan, porque pensaban que dar información postergaría el momento en que serían eliminados, o porque no sabían nada y esperaban que un nombre o una dirección les permitiría seguir viviendo. El filme expone los efectos destructivos de la tortura. No se trata de traiciones sino de negociaciones para sobrevivir que quienes no hemos sufrido esas atrocidades tenemos poco derecho a juzgar. El filme no juzga sino que muestra lo que pasó ahí adentro. Como nota Schwarzböck (2007: 27, 31), hay una suspensión del heroísmo y de la villanía. En el infierno del chupadero los prisioneros están obligados a compartir situaciones inhumanas con los que los delataron, a desconfiar el uno del otro.

Una "quebrada/o" es una persona que se quiebra bajo tortura, habla, y suele colaborar con sus verdugos. No solo hubo prisioneros quebrados. Podemos hablar de una sociedad quebrada, algo que quizás muchos prefieran no enfrentar y olvidar. Pero no es fácil borrar esas manipulaciones perversas del terror y la represión, incluyendo sus efectos a largo plazo. Podemos mirar a la sociedad como la "zona gris" de los campos Nazis que describiera Primo Levi (2004: 83-85), una zona de privilegio y diferentes niveles de colaboración, un espacio de ambigüedad. Al analizar la estructura y el funcionamiento del terrorismo de Estado quizás podamos identificar, como lo hiciera Levi, las líneas borrosas entre "nosotros" (los buenos) y "ellos" (los malos) para poder entender mejor que pasó y por qué pasó. Podemos ver en el filme un llamado a reflexionar sobre nuestras quebraduras.

El filme también muestra que en los infiernos más profundos florecen la compasión y la solidaridad. Es difícil no sentir empatía con el comportamiento de cada uno de los prisioneros. Compartiendo sus miserias y angustias, se dan ánimos, se ayudan a comer, cuidan a los que están enloqueciendo, y se contienen el uno a otro para evitar más castigos. La fuga es el ejemplo 
máximo de solidaridad, ya que son dos los prisioneros que la planean y dirigen pero se aseguran de llevar a los otros dos que estaban aterrorizados, derrotados, y no se animaban a escapar. Caetano dice que según el libro de Tamburrini "había una suerte de acostumbramiento en los prisioneros que es quizá una metáfora de lo que le ocurrió a la sociedad en ese momento" (en Schwarzböck, 2007: 80). Algo para considerar al analizar cómo actuó la gente. Una vez afuera, corriendo desnudos en medio de una noche de lluvia torrencial, una mujer se arriesga a responder al golpe en su puerta $\mathrm{y}$, sin hacer preguntas, le da a uno de los fugitivos algunas ropas y dinero para que se tome un taxi - un desafío al acostumbramiento que menciona Caetano y un riesgoso acto que ayudó a la fuga, comparable a las llaves solidarias mencionadas al discutir Kamchatka.

Caetano comenta que se trata de una "fuga triste" porque "no se fugan para vivir en libertad. Afuera no los esperan ni aplauso ni gloria" (en Schwarzböck, 2007: 77). Al cierre del filme se dan algunos datos sobre los que escaparon, adónde se fueron, dónde viven, qué hacen. También se dice que tres de ellos testificaron en el juicio a las juntas militares. Nos recuerdan que su fuga significó sobrevivir, convertirse en testigo, y contribuir al esclarecimiento de la verdad y la posibilidad de justicia. En cuanto a la contribución de Crónica en escribir memorias de la dictadura, Claudio Tamburrini piensa que el cine debe reflejar toda la información que ya se ha obtenido por los juicios y testimonios de sobrevivientes:

Si hoy se siguieran haciendo películas donde sólo se relata ese conflicto principal - acá están los malos, los torturadores; y acá están los buenos, las víctimas -, sería un ejercicio inútil, una utilización poco provechosa de un medio tan fuerte como el cine. Sería una memoria inercial, no activa; no recuperadora, ni generadora de debate". (en Kairuz, 2006)

Crónica es un ejemplo de un cine que contribuye a una memoria "ejemplar" aportando nuevos elementos para generar reflexión y debate sobre cómo recordamos esa época y cómo usamos esas memorias.

\section{5. ¿Que viene ahora?}

Si pensamos cómo el cine argentino ha reconstruido y transmitido las memorias de la dictadura, podemos afirmar que las películas de ficción han ubicado en la esfera pública varias temáticas sobre los años del terror. En particular, ciertas producciones recientes han sido claves en incorporar nuevos temas y nuevas perspectivas para temas ya tratados. Y parecería que continúa el interés por mirar a la dictadura a través del cine. A pesar de que 
muchos fomentan la idea de que ya hemos tenido demasiado de ese pasado y que todo lo que tenía que decirse ya está dicho, muchos cineastas quieren reconstruir esa historia de acuerdo a sus visiones sobre la misma. Esto es evidente en una generación de jóvenes realizadores que están representando al pasado desde la perspectiva de su mirada generacional. Estamos empezando a ver la dictadura por aquellos que la recuerdan como niños o a quienes se la han contado sus mayores, maestros, y los medios.

Específicamente en el cine de ficción, quedan muchos temas por tocar o que necesitan verse con nuevos puntos de vista: las múltiples facetas de la complicidad e indiferencia de los civiles; los efectos a largo plazo del terror; las experiencias de los que sobrevivieron tortura y desaparición; cómo las familias de activistas fueron afectadas; cómo el terror moldeó y alteró lo cotidiano; cuáles fueron las vivencias de las "personas comunes" y de los que todavía dicen "los militares no me hicieron nada"; cómo la gente procesó ser testigo del horror, como reaccionaron los que presenciaron el secuestro de alguien en la vía pública; las memorias de los vecinos de los centros clandestinos de tortura, la mayoría de los cuales funcionaban en zonas densamente populadas (el caso de la vecina solidaria en Crónica de una fuga); las experiencias de los militantes de la clase obrera, de donde proviene el porcentaje más alto de desaparecidos; detalles sobre los empresarios que se beneficiaron por las políticas económicas de la dictadura; debates críticos sobre activismo y lucha armada. No se ha dicho todo sobre este pasado. Hay miles de historias que esperan ser escuchadas y contadas. Siempre surgen formas distintas para pensar y representar la dictadura, nuevos enfoques para decir algo sobre un evento histórico de tal magnitud. Basta mencionar las docenas de películas sobre el Holocausto y la Guerra de Vietnam.

Además de analizar producción y texto, necesitamos investigar distribución y recepción. Entradas vendidas, cantidad de espectadores, y opiniones de los críticos no miden la circulación real de estos filmes, la vida e itinerarios de los mismos. Las salas cinematográficas no son los únicos espacios para verlos. Están los festivales, la televisión, las escuelas, el alquiler y venta de DVD, la bajada de películas de la red. Sabemos poco sobre quienes quieren ver películas sobre la dictadura. ${ }^{22} \mathrm{Y}$ el gran interrogante es cómo las audiencias interpretan y son afectadas por esas imágenes. Este es un terreno poco investigado y las preguntas iniciales para un nuevo estudio deberían considerar: a quiénes le hablan estos filmes, quién los mira, las conversaciones

${ }^{22}$ Quien quiere ver películas sobre la dictadura? es un video que sigue a la actriz de Garage Olimpo, Antonella Costa, investigando el interés en los filmes con esta temática. Pasó una tarde en las puertas de varios ex-centros clandestinos de detención de Buenos Aires entrevistando a la gente que pasaba por ahí (García, 2005). 
que generan, cómo los espectadores interpretan y dan significado a los textos cinematográficos, lo que enseñan. El conocimiento sobre la recepción y el uso de los filmes es esencial para poder evaluar el papel que juegan en el proceso de transmisión y [re]construcción de memorias.

Diana Kordon (2007), quien ha estado trabajando por más de tres décadas en los efectos sicológicos de la represión política, afirma que la memoria de la dictadura es muy insistente y que esta insistencia demuestra que el impacto de la dictadura todavía está presente y que hay marcas profundas en varios aspectos de la vida social cotidiana. Mientras esas memorias sigan insistiendo, tiene sentido pensar que el cine nos traerá nuevas representaciones del pasado. Los cineastas que insisten en documentar ese período histórico y sus secuelas moldearán lo que vendrá en recreaciones ficcionales del terror y nos entregarán nuevas páginas del libro de texto sobre la dictadura.

\section{Referencias bibliográficas}

Aguilar, Gonzalo (2006), Otros mundos: un ensayo sobre el nuevo cine argentino. Buenos Aires: Santiago Arcos Editor.

Arditti, Rita (1999), Searching for Life. Berkeley: University of California Press.

Arendt, Hannah (2004), "From Eichman in Jerusalem: A Report on the Banality of Evil”, en Nancy Scheper-Hughes; Philippe Bourgois (coords.), Violence in War and Peace. Oxford: Blackwell, 91-100 [11963].

Baumeister, Roy F.; Stephen Hastings (1997), "Distortions of Collective Memory: How Groups Flatter and Deceive Themselves", en James W. Pennebaker et al. (coords.), Collective Memory of Political Events; Social Psychological Perspectives. New Jersey: Lawrence Erlbaum Associates, 277-293.

Bellon, Emilio A. (2005), "Cautiva propone una mirada profunda sobre el doloroso pasado", Página 12 (http://www.pagina12.com.ar/diario/suplementos/rosario/12-1044-2005-11-21.html; accedido en 10/1/07).

Blejman, Mariano (2006), "Crónica de una fuga, ahora selección oficial de Cannes", Página 12 (http://www.pagina12.com.ar/diario/suplementos/espectaculos/5-2410-2006-04-28.html; accedido en 28/04/09).

Calveiro, Pilar (1998), Poder y desaparición. Buenos Aires: Colihue.

Depetris Chauvin, Irene (2006), "Los chicos crecen. La generación de los hijos y el cine de la postdictadura”, en Cecilia Macón (coord.), Trabajos de la memoria: arte y ciudad en la postdictadura argentina. Buenos Aires: Ladosur, 99-118.

Fentress, James; Chris Wickham (1992), Social Memory. Oxford: Blackwell.

Ferro, Marc; Jean Planchais (1997), Les Médias et L’histoire; Le poids du passé dans le chaos de l'actualité. Paris: CFPJ. 
García, Eugenia (2004), "Entrevista con Julia Solomonoff, que filma su primer largometraje”, Página 12 (http://www.pagina12.com.ar/diario/espectaculos/6-36623-2004-06-13.html; accedido en 13/07/09).

García, Lorena (2005) “Confesiones de la memoria”, La Nación (http://www.lanacion. com.ar/741004; accedido en 23/09/09).

Getino, Octavio (2005), Cine Argentina: entre lo posible y lo deseable. Buenos Aires: Ediciones CICCUS.

Gorodischer, Julián (2005), "Una militante de H.I.J.O.S. y la protagonista del film conversan sobre Cautiva”, Página 12 (http://www.pagina12.com.ar/diario/suplementos/espectaculos/5-772-2005-10-20.html; accedido en 20/10/09).

Habermas, Jürgen; Adam Michnik (1994), "Overcoming the Past”, New Left Review, 203, 3-16.

Halbwachs, Maurice (1992), On Collective Memory. Trad. e coord. Lewis A. Coser. Chicago: The University of Chicago Press.

Hansen, Miriam Bratu (2000), "Schindler's List Is Not Shoah: The Second Commandment, Popular Modernism, and Public Memory”, en Marcia Landy (coord.), The Historical Film; History and Memory in Media. New Brunswick, NJ: Rutgers UP, 201-217. Huyssen, Andreas (1995), Twilight Memories; Marking Time in a Culture of Amnesia. New York: Routledge.

Igartúa, Juanjo; Darío Páez (1997), “Art and Remembering Traumatic Collective Events: The Case of the Spanish Civil War”, en James W. Pennebaker et al. (coords.), Collective Memory of Political Events; Social Psychological Perspectives. New Jersey: Lawrence Erlbaum Associates, 79-101.

Jakubowicz, Eduardo; Laura Radetich (2006), La bistoria argentina a través del cine: las "visiones del pasado" (1933-2003). Buenos Aires: La Crujía.

Kaiser, Susana (2005), Postmemories of Terror: A New Generation Copes with the Legacy of the "Dirty War". New York: Palgrave Macmillan.

Kaiser, Susana (2007), "Postmemories in Images". Paper presentado en la conferencia de Latin American Studies Association (LASA). Montreal, Canada, 5-8 de septiembre.

Kaiser, Susana (2008), "Memory Shots: The Camera as Historian in Post-Dictatorship Argentina". Paper presentado en la conferencia "Narratives of Violence and Reconciliation in Contemporary Latin America". University of Oregon, Eugene. 31 de enero -2 de febrero.

Kairuz, Mariano (2006), “Adrian Caetano revisita los '70”, Página 12 (http://www. pagina12.com.ar/diario/suplementos/radar/9-2940-2006-04-16.html; accedido en 16/4/09).

Kollman, Raúl (2000), “Los querían blanquitos y recién nacidos”, Página 1 (http://www. ser2000.org/protect/Archivo/d000e702.htm; accedido en 9/01/10).

Kordon, Diana (2007), Presentácion en el panel “Memoria y Espacios Sociales," Centro Cultural de la Cooperación, Buenos Aires, 26 de septiembre. 
Koza, Roger Alan (2004), Con los ojos abiertos: crítica cinematográfica de algunas películas recientes. Córdoba, Argentina: Editorial Brujas.

Landy, Marcia (coord.) (2000), The Historical Film; History and Memory in Media. New Brunswick, NJ: Rutgers UP.

Levi, Primo (2004), “The Gray Zone”, en Nancy Scheper-Hughes; Philippe Bourgois (coords.), Violence in War and Peace. Oxford: Blackwell, 91-100.

López, Marcela; Alejandra Rodriguez (2009), Un país de película: la historia argentina que el cine nos contó. Buenos Aires: Del Nuevo Extremo.

Loshitsky, Yosefa (1999), "Fantastic Realism; Schindler's List as Docudrama”, en Alan Rosenthal (coord.), Why Docudrama? Fact Fiction on Film and TV. Carbondale: Southern Illinois UP, 357-369.

Manzano, Valeria (2009), "Garage Olimpo o cómo proyectar el pasado sobre el presente (y viceversa)", en Claudia Feld; Jessica Stites Mor (coords.), El pasado que miramos: memoria e imagen ante la historia reciente. Buenos Aires: Paidós, 151-180.

Molas y Molas, María; Mariano Bersotti (2006), "Los hechos”, en Maria Paulinelli (coord.), Cine y Dictadura. Córdoba, Argentina: Comunicarte editorial, 21-46.

Pavlovsky, Eduardo (1999), "Sobre la complicidad civil con el terrorismo de Estado", Página 12 (http://www.pagina12.com.ar/1999/suple/psico/99-06/99-06-24/psico01. htm; accedido en 24/06/09).

Ranalletti, Mario (1999), "La construcción del relato de la historia argentina en el cine, 1983-1989”, Film-Historia, IX(1), 3-15.

Respighi, Emanuel (2005), "Reportaje a la realizadora Julia Solomonoff a propóstio de "Hermanas", su opera prima recientemente estrenada", Página 12 (http://www. pagina12.com.ar/diario/espectaculos/6-50463-2005-05-02.html; accedido en 02/05/09).

Rosenthal, Alan (coord.) (1999), Why Docudrama? Fact Fiction on Film and TV. Carbondale: Southern Illinois University Press.

Rosentone, Robert (2000), "The Historical Film: Looking at the Past in a Postliterate Age”, en Marcia Landy (coord.), The Historical Film; History and Memory in Media. New Brunswick, NJ: Rutgers University Press, 201-217.

Sartora, Josefina; Silvina Rival (2007), Imágenes de lo real: la representación de lo político en el documental argentino. Buenos Aires: Libraria.

Schwarzböck, Silvia (2007), Estudio crítico sobre Crónica de una fuga. Buenos Aires: Picnic editorial.

Soto, Moira (2006), "La caída del muro", Página 12 (http://www.pagina12.com.ar/ diario/suplementos/las12/13-2572-2006-03-29.html; accedido en 24/03/10).

Sturken, Marita (1997), Tangled Memories; The Vietnam War, the AIDS Epidemic, and the Politics of Remembering. Berkeley: University of California Press.

Tal, Tzvi (2005), "Alegorías de memoria y olvido en películas de iniciación: Machuca y Kamchatka", Aisthesis: Revista chilena de investigaciones estéticas, 38, 134-149. 
Tessa, Sonia (2005), “Julia elige Rosario”, Página 12 (http://www.pagina12.com.ar/ diario/suplementos/las12/13-2076-2005-07-20.html; accedido en 15/07/09).

Todorov, Tzvetan (1995), Les abus de la mémoire. Paris: Arléa.

Varea, Fernando G. (2006), El cine argentino durante la dictadura militar 1976-1983. Rosario: Editorial Municipal de Rosario.

Verbitsky, Horacio (1997), "Militares, Civiles y el Miedo", en Juan Gelman; Mara La Madrid (coords.), Ni el flaco perdón de Dios; Hijos de desaparecido. Buenos Aires: Planeta, 124-135.

Verzero, Lorena (2009), "Estrategias para crear el mundo: la década del setenta en el cine documental de los dos mil", en Claudia Feld; Jessica Stites Mor (coords.), El pasado que miramos: memoria e imagen ante la bistoria reciente. Buenos Aires: Paidós, 181-217.

\section{Filmografia}

Cautiva, Gastón Biraben, 2003.

Crónica de una fuga, Israel Adrián Caetano, 2006.

Hermanas, Julia Solomonoff, 2004.

Kamchatka, Marcelo Piñeyro, 2002. 